\title{
RECURSOS INFORMACIONAIS E A ATUAÇÃO DOS PROFISSIONAIS NO MERCADO DE COMUNICAÇÃO DIGITAL
}

\author{
Nathália Matychevicz Chemin de Barros Caldas* \\ Tomás Sparano Martins** \\ Flávio Luiz von der Osten*** \\ Paola Andrea Moreno Espinoza**** \\ Andreia Bolivar Pedroso D'Amico ${ }^{* * * * * *}$
}

RESUMO: Para se manterem competitivos, gerando soluções menos onerosas e que estejam em consonância com as expectativas de seus stakebolders, os publicitários que atuam com marketing digital buscam informações em publicações específicas da área. No entanto, há ainda a necessidade de entender como esses profissionais avaliam os recursos informacionais. Sob a luz da Visão Baseada em Recursos (VBR) e entendendo a importância de legitimidade organizacional, objetivou-se entender como os recursos informacionais, tais como publicações especializadas, são utilizados nas empresas para conferi-las vantagem competitiva. Para isso, foram realizadas entrevistas estruturadas com quinze publicitários de marketing digital de médias e grandes agências do Paraná com atuação local e nacional. Ademais, foi realizado um estudo do conteúdo e uma análise específica da relevância do relatório The SoDA Report, concluindo que seu valor está ligado à questão da legitimidade que ele confere às agências que os utilizam. A fim de analisar as informações contidas nas publicações, considerou-se o quanto elas são valiosas, raras, inimitáveis e organizacionalmente exploráveis (VRIO). Enfim, foi identificado que esses recursos informacionais atendem ao critério VRIO à medida que derivem de uma fonte confiável e que sejam relevantes. Esse artigo amplia a literatura da VBR ao mostrar em que medida os recursos informacionais são valorizados, principalmente ao conferir legitimidade, o que é indispensável em um mercado dinâmico.

PALAVRAS-CHAVE: Recursos informacionais; VBR; The SoDA Report; Legitimidade; Publicidade.

\footnotetext{
Especialista em Gestão Estratégica pela Universidade Federal do Paraná (UFPR), Brasil.

* Docente Doutor na Universidade Federal do Paraná (UFPR), Brasil.

*** Mestrando em Administração pela Universidade Federal do Paraná (UFPR), Brasil. E-mail: flavioosten@gmail.com

***** Mestranda em Administração pela Universidade Federal do Paraná (UFPR), Brasil.

****** Mestranda em Administração pela Universidade Federal do Paraná (UFPR), Brasil.
} 


\title{
INFORMATION RESOURCES AND PROFESSIONALS' PERFORMANCE ON DIGITAL COMMUNICATION MARKETING
}

\begin{abstract}
Advertisers dealing with digital marketing should be deeply informed in specific publications so that they continue being competitive, producing low-cost solutions and meeting their stakeholders' expectations. However, the manner these professionals assess information resources should be better understood. From the point of view of the Resource-Based Vision and understanding the importance of organizational legitimacy, current article discusses how financial resources, such as specialized publications, are employed by firms for competitive advantages. Structured interviews with fifteen digital marketing advertisers of medium- and small-sized firms in the state of Paraná, Brazil, with local and national activities, were undertaken. A content study and a specific analysis on The SoDA Report were prepared. Results show that its relevance is linked to the issue of legitimation that it confers to the firms. Analysis of information in publications provided their degree in value, scarcity, inimitable and organizationally exploitability. Information resources actually attended to the above-mentioned criteria according to their relevance and in proportion to their origin from a reliable source. Current paper broadens RBV literature since it reveals that degree information resources are valorized, especially in conferring legitimacy, which is indispensable within a dynamic market.
\end{abstract}

KEY WORDS: Informational resources; RBV; The SoDA Report; Legitimation; Publicity.

\section{INTRODUÇÃO}

A internet é a principal responsável pela dinamicidade e maior complexidade dos mercados atuais (LEEFLANG et al., 2014). Porém, segundo Day (2011) há uma lacuna entre essa complexidade gerada pela internet e os processos de marketing necessários para compreendê-la e geri-la. Entende-se que o marketing digital - o qual incluiu a internet e as tecnologias digitais como instrumentos de marketing - é uma forma importante para se atuar nesse novo cenário de complexidade.

No entanto, para que as ações de marketing digital sejam efetivas nos mercados complexos, os profissionais de publicidade necessitam oferecer soluções mais criativas e menos custosas apoiadas em ideias inovadoras. Além disso, essas ideias devem estar em consonância com o mercado (clientes e concorrentes), caso 
contrário as soluções que a empresa apresenta não terão legitimidade frente aos entes do mercado (SCOTT, 2001). A fim de suprir tal necessidade e se manterem competitivos, esses profissionais buscam informações em publicações físicas e digitais, as quais são especializadas em publicidade e marketing.

Essa busca por se manter competitivo - busca de vantagem competitiva pode ser analisada sob a ótica da Visão Baseada em Recursos (VBR). A VBR afirma que os recursos podem gerar vantagem competitiva para as organizações se forem valiosos, raros, inimitáveis e não substituíveis (BARNEY, 1991).

De acordo com Morgan (2012), um dos tipos de recursos que podem ser explorados organizacionalmente são os recursos informacionais, os quais referemse às informações sobre clientes, concorrentes, fatos ocorridos, ambiente e outros que servem de insumos importantes para as atividades organizacionais, tais como: precificação, publicidade, desenvolvimento de produtos e planejamento (MORGAN, 2012). Esses recursos são considerados estratégicos à medida que atendam os critérios da VBR (BARNEY, 1991).

Os recursos informacionais bem como as atividades de marketing relacionadas, tais como: aquisição e gerenciamento da informação de marketing, têm recebido bastante atenção acadêmica, especialmente quanto: (1) ao efeito das atividades de informação sobre o desempenho organizacional e (2) aos fatores que influenciam o gerenciamento da informação (BOCCONCELLI et al., 2016). Por exemplo, Wang, Gupta e Grewal (2017) encontraram relação positiva entre recursos informacionais trazidos pela contratação de executivos de marketing e vendas e o desempenho organizacional. Além disso, Friske (2015) encontrou que os recursos informacionais são fundamentais para a implementação estratégica, tendo papel mais importante que os recursos financeiros.

Quanto a gestão de informação, Mithas, Ramasubbu e Sambamurthy (2011) notaram que a capacidade de gestão de informações tem influência positiva sobre gestão de clientes, processos e gestão de desempenho. Krush, Agnihotri e Trainor (2016) encontraram uma relação positiva entre os dashboards de marketing e a habilidade em gestão de informações.

No entanto, nota-se que a maneira como os recursos informacionais proporcionam desempenho organizacional são colocados em segundo plano. $\mathrm{Ou}$ seja, embora entenda-se que os recursos informacionais gerem resultados positivos 
para a organização e tenha-se estudado como gerenciar a aquisição e uso desses recursos (BOCCONCELLI et al., 2016), não se tem clareza sobre como esses recursos melhoram o desempenho.

Além disso, essa questão é especialmente importante quando se tratam de recursos informacionais que estão disponíveis em larga escala (como revistas e newsletters) e à luz da VBR. Isso porque, a VBR apregoa que, para um recurso gerar vantagem competitiva (desempenho superior de longo prazo), ele deve ser raro e inimitável, o que claramente não é o caso dos periódicos como revistas e newsletters. Ora, se um determinado recurso pode ser acessado por qualquer concorrente como poderia gerar desempenho superior?

Dessa forma, o objetivo desse artigo é entender como os recursos informacionais, tais como publicações especializadas, são utilizados nas empresas para conferi-las vantagem competitiva. Para alcançar esse objetivo, foram realizadas entrevistas estruturadas com quinze publicitários de marketing digital de médias e grandes agências do Paraná, com atuação local e nacional.

Adicionalmente, foi realizado um estudo do conteúdo e uma análise específica da relevância do relatório The SoDA Report (SoDA) como um recurso estratégico. O SoDA é um relatório internacional com grande relevância na área. Essa relevância é justificada por fatores como: (1) constância de publicação, (2) abrangência (entre maio de 2014 e maio de 2015 o número de visualizações chegou a 330.000), e (3) por contar com colunistas e entrevistados de grandes empresas, como Adobe ${ }^{\circledR}$, Microsoft ${ }^{\circledR}$, PwC, Deltek ${ }^{\mathrm{TM}}$, Symantec ${ }^{\mathrm{TM}}$, Heineken ${ }^{\circledR}$, Nando's, LVMH, Google, L'Oreal e Mashable.

O artigo está dividido em cinco partes: (1) introdução; (2) o referencial teórico, o qual está dividido em dois subitens: (a) visão baseada em recursos e informações como recursos e (b) legitimidade como recurso; (3) método; (4) resultados e discussão; e por fim (5) considerações finais.

\section{REFERENCIAL TEÓRICO}

Neste capítulo são apresentadas as teorias que servem como base para interpretação e discussão dos resultados dessa pesquisa. Primeiramente, apresentamse os principais conceitos referentes à visão baseada em recursos. Na sequência, 
discorre-se sobre os recursos informacionais e por fim, apresenta-se uma breve explanação acerca da legitimidade.

\subsection{VISÃO BASEADA EM RECURSOS}

A visão baseada em recursos (VBR) tem como argumento principal que a vantagem competitiva sustentável decorre de recursos valiosos, raros, inimitáveis e não substituíveis (BARNEY, 1991). Os recursos são os ativos controlados pela empresa, que servem como entradas para as capacidades organizacionais (GRANT, 1991).

Para ser considerado valioso, um recurso precisa proporcionar à empresa o desenvolvimento de estratégias que resultem na redução de seus custos ou no aumento de suas vendas, em um nível superior àquele que ela conseguiria caso não tivesse acesso a tal recurso (KOZLENKOVA; SAMAHA; PALMATIER, 2013). Quanto à raridade, são avaliados como raros aqueles recursos que são controlados por um número pequeno de concorrentes ou potenciais concorrentes, ou seja, são recursos cujo acesso é restrito (BARNEY; HESTERLY, 2012).

A inimitabilidade dos recursos está associada (1) às questões de formação histórica - alguns recursos só podem ser desenvolvidos durante longos períodos de tempo; (2) à ambiguidade causal - os mecanismos para o desenvolvimento de alguns recursos podem não ser evidentes; ou (3) à complexidade social - quando recursos não podem ser comprados e vendidos porque estão inseridos em redes sociais complexas (BARNEY, 1991, 2001).

Sobre a característica de ser não substituível, refere-se ao fato do recurso não possuir substitutos estratégicos equivalentes, ou seja, refere-se à singularidade do recurso (BARNEY, 1991). Em estudos recentes, autores como Barney e Hesterky (2012) e Kozlenkova (2013) passaram a considerar essa característica como parte do critério de inimitabilidade do recurso (BARNEY; HESTERLY, 2012; KOZLENKOVA et al., 2013).

Ademais, Barney e Hesterly (2012) incluíram mais uma característica que tornam os recursos uma fonte de vantagem competitiva: a organização, a qual indica que a organização precisa possuir procedimentos e políticas necessários 
para explorar o recurso (BARNEY; HESTERLY, 2012). Com a inclusão desse item e o entendimento de que ser não substituível é parte de ser inimitável, tem-se o modelo VRIO (valor, raridade, inimitabilidade e organização) para avaliação de recursos segundo a VBR.

No próximo tópico, serão apresentados os recursos informacionais que, segundo Morgan (2012), é um dos tipos de recursos de marketing que, por sua vez, são definidos como "ativos disponíveis aos profissionais de marketing, e outros na organização que [...] podem ser usados para criar resultados valiosos" (MORGAN, 2012, p. 104).

\subsection{RECURSOS INFORMACIONAIS}

Para Morgan (2012, p. 105), recursos informacionais são "informações referentes a dados, tais como fatos, proposições axiomáticas e símbolos que podem ser transmitidos sem a perda de integridade desde que as regras sintáticas para as decifrar sejam conhecidas". Por outro lado, na literatura profissional existe uma diferença entre "dados", ou seja, os fatos referentes a aspectos funcionais, e "informação", que seriam os dados processados e prontos para uso (UBAVIĆ, 2015).

Neste estudo, utiliza-se a definição de Morgan (2012), pois para a teoria de base utilizada (VBR) é mais importante se um recurso pode trazer vantagem competitiva do que diferenças semânticas.

Em um recente estudo Bocconcelli et al. (2016), ao avaliarem 310 artigos sobre marketing em pequenas e médias empresas, propuseram que as atividades de informação de marketing (i.e. aquisição e gerenciamento da informação de marketing) são atividades de marketing estratégico, ou seja, estão no mesmo nível de atividades como segmentação de mercado e posicionamento.

Além disso, perceberam que o estudo dessas atividades tem recebido bastante atenção acadêmica especialmente quanto (1) ao efeito das atividades de informação sobre o desempenho organizacional e (2) fatores que influenciam o gerenciamento da informação (BOCCONCELLI et al., 2016).

Dentro do campo de estudo do marketing estratégico, o estudo de recursos informacionais não é recente. Por exemplo, informações sobre clientes e 
concorrentes são bastante importantes e podem ser vistas desde as pesquisas sobre orientação ao mercado (KOHLI; JAWORSKI, 1990; NARVER; SLATER, 1990).

No próximo tópico, apresenta-se o conceito de legitimidade, o qual faz parte da Teoria Institucional das Organizações.

\subsection{LEGITIMIDADE}

A Teoria Institucional das Organizações fornece uma visão rica e complexa das organizações (ZUCKER,1987). Segundo essa teoria, as organizações são influenciadas por pressões normativas provenientes tanto do ambiente interno quanto externo (ZUCKER,1987). Essas pressões levam as organizações a adotarem elementos de legitimidade.

A legitimidade é definida como "a percepção ou suposição generalizada de que as ações de uma entidade são desejáveis, adequadas ou apropriadas, dentro de algum sistema de normas, valores, crenças e definições socialmente construídas" (SUCHMAN, 1995, p. 544). Portanto, há legitimidade quando o ator, indivíduo ou organização, age em conformidade com o que é considerado aceitável pelo grupo social em que está inserido.

O institucionalismo organizacional enfatiza que a legitimidade organizacional depende do grau de convergência entre a estrutura de uma organização e as instituições de seu ambiente. Além disso, destaca também a importância do quanto tais instituições são legítimas nesse ambiente. Essas prerrogativas incrementam a capacidade de sobrevivência e facilitam o alcance de maiores resultados (ROSSONI, 2016). Por exemplo, no setor de publicidade, uma agência teria maior chance de sobrevivência se replicasse as práticas de outras agências.

Dessa forma, a legitimidade é considerada um conceito essencial para compreender o institucionalismo organizacional (SCOTT, 2008; SUCHMAN, 2008). Sua importância parte da premissa de que as organizações, além de recursos e de informações do ambiente, necessitam de aceitação e credibilidade para sobreviver e prosperar em seus ambientes sociais (SCOTT, 2001).

Tal premissa é creditada a Weber (1991), que indica que as práticas sociais são orientadas por regras aceitas e incluídas como socialmente válidas, referindo- 
se à aceitação das formas de conduta de atores sociais ou organizações que atuam como agentes dentro de uma realidade social (ROSSONI, 2016).

Ao utilizar constantemente recursos do ambiente, as organizações são avaliadas pela sociedade, para verificar se as ações, produtos, serviços ou resultados organizacionais são apropriados ou socialmente úteis (PFEFFER; SALANCIK, 1978). No entanto, para garantir legitimidade, somente são consideradas relevantes as avaliações daquelas organizações ou indivíduos que contribuem com recursos que dão suporte às atividades organizacionais ou que consomem seus produtos, devido a dependência e relação direta que têm com a sobrevivência da organização (ROSSONI, 2016).

Por isso, a legitimidade organizacional se dá como consequência da interpretação de ações em comparação com valores socialmente legítimos (PFEFFER; SALANCIK, 1978). Dessa maneira, as organizações que incorporam elementos legitimados em suas estruturas formais aumentam o compromisso dos participantes internos, assim como de seus constituintes externos.

Como consequência, protegem a organização de ter condutas questionadas e ajudam-na a aumentar seus recursos, a maximizar sua legitimidade e a incrementar seu potencial de sobrevivência (MEYER; ROWA, 1977).

Para Scott (2008), a legitimidade na abordagem da dependência de recursos é tratada como mais um recurso que a organização extrai de seu ambiente organizacional. Porém na abordagem institucional, "legitimidade não é uma "commodity" que pode ser possuída ou trocada, mas sim uma condição que reflete a consonância percebida com as regras relevantes e leis, suporte normativo, ou o alinhamento com estruturas cultural-cognitivas" (SCOTT, 2008, p. 60).

Diante do exposto, admite-se a legitimidade como um elemento constituído e constitutivo, em co-dependência com recursos e processos interpretativos; podendo olhar o aspecto constitutivo, uma vez que diversos fatores ou recursos adquirem a propriedade de ser valiosos somente quando são legitimamente interpretados como valiosos (CRUBELLATE; PASCUCCI; GRAVE, 2008). Ou seja, quanto maior for a legitimidade alcançada por uma organização mais fácil será conseguir novos recursos, por sua vez, quanto maior for a base de recursos da empresa maior será sua legitimação social. 
Ainda, a legitimidade é um conceito central para a análise dos recursos, já que sem legitimidade os recursos e competências não podem ser julgados quanto a seu valor e não podem ser estrategicamente selecionados, acumulados e dispostos (CRUBELLATE et.al, 2008). Dessa forma, os recursos informacionais só poderão ser considerados valiosos e úteis se forem legítimos.

A procura pela maximização de recursos, pode fazer com que as organizações sigam orientações e adotem escolhas semelhantes, ficando, portanto, sujeitas às mesmas condições do meio e do processo de interpretação (CRUBELLATE et.al, 2008). Esse processo pode ser entendido como isoformismo, ou seja, o processo pelo qual as organizações que atuam em um mesmo campo organizacional e, consequentemente, recebem as mesmas pressões e restrições institucionais, tendem a homogeneizar suas estruturas visando alcançar a legitimidade (DIMAGGIO; POWELL,1983).

\section{MÉTODO}

Para atingir o objetivo dessa pesquisa que consiste em entender como os recursos informacionais, tais como publicações especializadas, são utilizados nas empresas para conferi-las vantagem competitiva, utilizou-se os métodos de entrevista e análise de conteúdo.

A entrevista é uma técnica qualitativa que tem por objetivo explorar o que as pessoas sabem, opinam, creem, sentem, desejam e esperam, para coletar informações que contribuam ao problema de pesquisa (VEIGA; GONDIM, 2001; RODRÍGUEZ,2011). É uma técnica realizada por meio da comunicação interpessoal entre o pesquisador e o sujeito de estudo para assimilar a informação obtida com a maior exatidão possível (RODRÍGUEZ, 2011).

Marconi e Lakatos (2007) tipificaram as entrevistas segundo o propósito do entrevistador em: entrevista padronizada ou estruturada, entrevista despadronizada ou não estruturada e a entrevista painel. Nesse estudo, realizou-se a entrevista estruturada para obter respostas dos entrevistados às mesmas perguntas por meio de um roteiro e formulário predeterminado, que permitiram que as respostas fossem analisadas e comparadas. 
Foram entrevistados 15 profissionais de comunicação e marketing digital de agências de publicidade no Paraná, para obter informação sobre suas percepções a respeito do conteúdo das publicações especializadas. Dessas entrevistas, 12 foram presenciais e 3 foram realizadas por meio de comunicação eletrônica.

Foram selecionados respondentes com cargos executivos nas agências de publicidade, tais como: diretores, gerentes e coordenadores de estratégia, operações, tecnologia e design. A razão para entrevistar membros da alta gestão é que eles são mais familiarizados com as ideias e valores da organização e, portanto, constituem uma amostra mais apropriada para o objetivo de pesquisas desse artigo (HAMBRICK; MASON, 1984).

Para analisar a informação obtida dos respondentes, realizou-se uma análise de conteúdo utilizando o software Atlas TI. A análise de conteúdo é uma técnica que permite interpretar diferentes tipos de registros de dados, como textos, transcrição de entrevistas, discursos, protocolos de observações ou de outros materiais que tem a capacidade de amalgamar conteúdos, que lidos e interpretados adequadamente, permitem conhecer diversos aspectos de uma unidade de análise (ABELA, 2002).

A análises de conteúdo desenvolveu-se a partir das seguintes etapas propostas pelo autor Pablo Cáceres (2008):

a) Seleção do objeto para análise do conteúdo, sendo neste caso o conteúdo das respostas dadas pelos quinze entrevistados;

b) Desenvolvimento da pré-análise, onde se realizou uma primeira tentativa de organizar o conteúdo e se estabeleceu indicadores que tratam de temas que emergiram na entrevista;

c) Definição dos segmentos do conteúdo que inicialmente foram caracterizados e posteriormente categorizados, relacionados e se estabeleceram inferências a partir deles; e por fim foi feita a revisão da literatura a fim de encontrar relações com os temas encontrados;

d) Estabelecimento de regras de análise que determinaram as condições para a criação de códigos, os quais foram usados como identificadores para categorizar o material;

e) Desenvolvimento de categorias, onde ordenou-se e classificou-se, de 
forma definitiva, o conteúdo previamente codificado;

f) Integração final dos achados onde todo o desenvolvimento analítico do conteúdo se tornaram os resultados do estudo.

Analisou-se também a publicação especializada SoDA com a finalidade de pesquisar seu conteúdo, as tendências de marketing digital, publicidade, design e tecnologia. Foram analisados os volumes das edições publicadas entre 2012 e 2015.

No próximo item desse artigo, tem-se os resultados obtidos aplicando os métodos apresentados, bem como a discussão dos mesmos e suas implicações para entender como os recursos informacionais, tais como publicações especializadas, são utilizados nas empresas para conferi-las vantagem competitiva.

\section{RESULTADOS E DISCUSSÃO}

Inicia-se pela discussão dos resultados da análise de conteúdo da transcrição das entrevistas. A fim de entender o posicionamento dos entrevistados, em primeiro lugar é importante identificar o ambiente de negócios onde as agências de publicidade de marketing digital estão inseridas - ou, pelo menos, o ambiente que é percebido pelos profissionais da área.

A percepção dos entrevistados sugere que o ambiente é extremamente competitivo, com concorrentes disputando ativamente as contas dos principais clientes. $\mathrm{O}$ ambiente também é volátil quanto à tecnologia. Além disso, pôdese concluir que um horizonte de 2 a 3 anos já é considerado longo prazo. Esta turbulência ambiental pode ser vista em vários trechos das falas, como por exemplo:

(Sobre ler SoDA Report...) "É uma leitura essencial pra ver como as outras agências estão no mercado, especialmente porque estamos todos os dias nos acotovelando com as concorrentes."

"A mídia programática que agora está em voga e muitos clientes e agências vão atrás como se fosse o Santo Graal, e não é, eu vi isso pela primeira vez lá fora em um evento já faz 3 anos, e agora virou uma realidade no Brasil, eu tentei antecipar, tanto é que eu disseminei isso e tenho orgulho disso." 
A principal implicação dessa percepção de turbulência para esse artigo é que as informações nesse contexto têm alta perecibilidade, o que gera pressão por velocidade.

As entrevistas foram analisadas partindo-se dessa percepção do ambiente e seguindo o modelo teórico VRIO. Todos os códigos e categorias foram agrupados de acordo com esse modelo teórico e estão resumidos na figura 1.

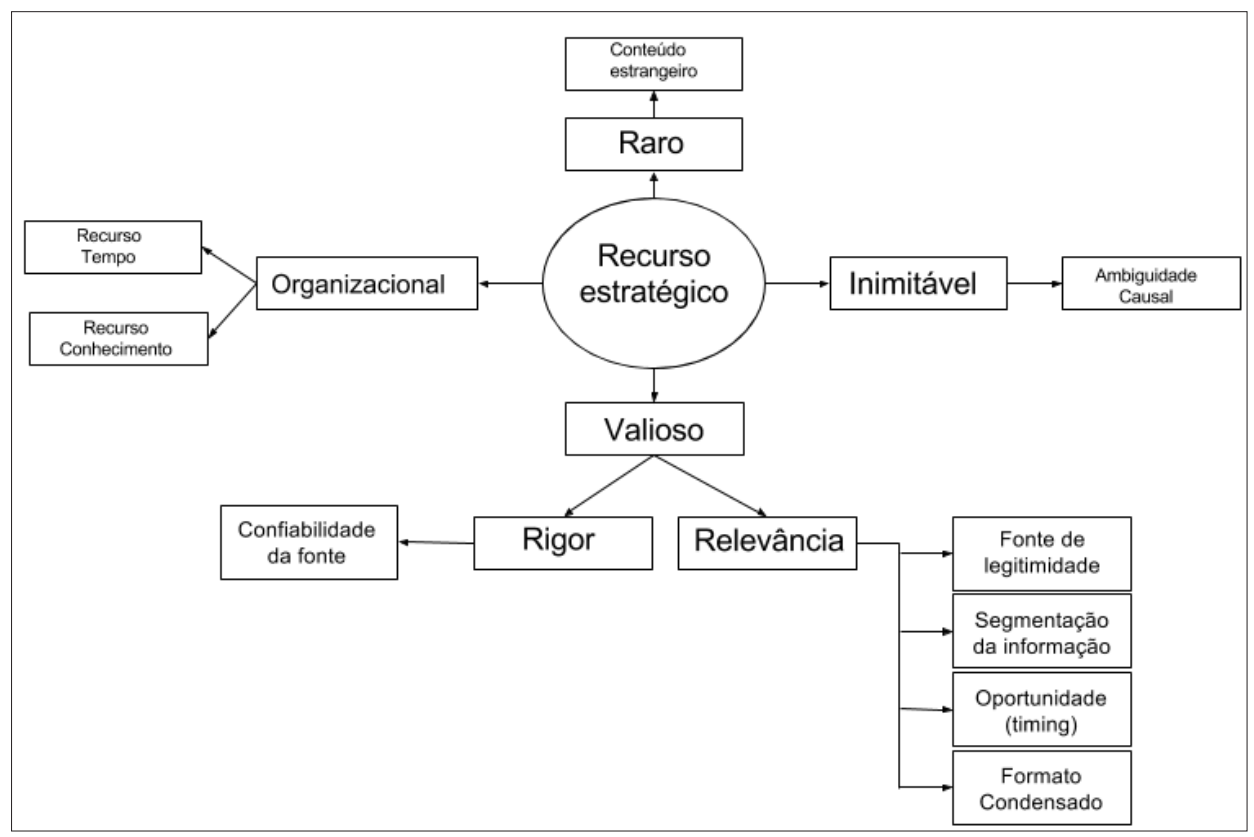

Figura 1. Falta o Título

Fonte: Elaborado pelos autores, 2016

Utilizando-se o modelo mencionado, o primeiro critério de análise das publicações especializadas foi o valor. Nas entrevistas realizadas nota-se que o valor possui diversas fontes. Uma publicação é considerada mais valiosa para o executivo à medida que for mais confiável e relevante.

A confiabilidade da publicação está atrelada a confiabilidade de sua fonte. No contexto observado, é comum o uso de informações secundárias, curadas por um terceiro, pois elas terão a chancela de um profissional considerado "válido". Esta questão da busca por confiabilidade pode ser percebida no recorte abaixo, quando o entrevistado foi inquerido sobre a fonte de suas leituras: 
[...] não leio de uma fonte só, eu vou no hub do Fabrício Teixeira e ele vai direcionando pra vários.

Nessa frase o entrevistado deixa claro que a opinião do curador é central em sua busca por informações.

Juntamente com o requisito de confiabilidade, tem-se a relevância como fator para analisar o valor de uma publicação. A relevância da publicação é tratada pelos publicitários de forma peculiar. A maneira como a relevância é tratada parece ser contingente ao cargo exercido. Para executivos com funções administrativas, nota-se mais interesse por informações sobre tendências de mercado. Enquanto que, para executivos com funções técnicas, percebe-se a busca por ferramentas ou informações específicas sobre o trabalho.

Analisando o conteúdo das entrevistas de executivos com funções técnicas, percebe-se o interesse por informações micro segmentadas. Isso significa que as informações devem tratar especificamente do tipo de trabalho que o profissional realiza, ou sobre determinado projeto que o profissional esteja realizando, naquele momento, para serem consideradas relevantes. Como por exemplo:

É uma absorção e leitura que é mais focada e pontual, geralmente você vai atrás de um assunto do seu interesse e vai mirando naquilo, $[\ldots]$.

Por outro lado, os executivos com funções administrativas inferem relevância sobre as publicações na medida em que essas conferem legitimidade perante os stakeholders. Vários entrevistados buscam informações macro sobre o mercado, as quais são usadas para legitimar suas agências frente a seus concorrentes ou clientes. Isso pode ser observado nos trechos abaixo sobre o SoDA report:

[...] pros nossos clientes temos levado o report SoDA pra provocar a curiosidade do lado deles, porque muitos deles estão em um processo de transformação digital.

O que achei mais legal é que é uma leitura confortável, porque você vê que os problemas que você está passando na sua agência são exatamente os mesmos que os outros estão passando, não é exclusividade sua, acontece com todo o mercado.

Aqui, ainda se percebe que, quando a valoração do conteúdo é devido à legitimidade, o tipo de informação buscada é menos funcional/técnico e mais 
macro ambiental. Nessas situações, são buscadas informações sobre tendências de mercado e de tecnologia. Em outras palavras, quando um publicitário busca recursos informacionais sobre tendências de mercado e tecnologia entende-se que ele esteja buscando formas de legitimar suas ações perante os clientes e demais stakebolders.

Outra forma de analisar a relevância da publicação especializada refere-se a sua extensão - número de palavras. Apesar do número de horas trabalhadas pelos profissionais do setor - resultado da pressão causada pela turbulência ambiental - os profissionais procuram informações atualizadas, desde que seu conteúdo seja curto. Essas inferências podem ser vistas nos exemplos:

Eu trabalho 10, 12, 13 horas por dia em média.

Quase todos os dias leio algo curto.

Quanto ao conteúdo, não é que ele seja relevante, ele é, mas você consegue também achar em outras referências mais espalhadas. $\mathrm{O}$ bom dele é que é condensado.

Analisando agora o segundo ponto do modelo VRIO, procurou-se inferir como os recursos informacionais podem trazer raridade. Embora não seja lógico entender o conteúdo de uma publicação especializada como raro - afinal o mesmo periódico pode ser adquirido por qualquer pessoa - os executivos procuram a informação mais exclusiva possível.

Isso fica claro pela busca de fontes estrangeiras e pela quantidade de fontes de informação diferentes que foram citadas (meio\&mensagem, Mashable, AdWeek, eMarketer, Uxdesign.cc, Advertising Age, Brainstorm9, Trendwatching, Think with Google, Clube da Criação, Forrester, VTEX e Acquia). Essa questão pode ser vista no trecho:

[...], acho que existe um abismo grande entre o que acontece lá fora e o nosso mercado, até mesmo em São Paulo.

Quanto à inimitabilidade do recurso, percebeu-se que os recursos informacionais podem auxiliar especialmente no mecanismo da ambiguidade causal, ou seja, os recursos informacionais em conjunto com outros podem gerar resultados difíceis de serem imitados pelos concorrentes. Neste caso, nota-se que os recursos informacionais unem-se aos recursos humanos e de conhecimento (já presentes na 
empresa) para, de maneira difusa, chegar a resultados positivos. Conforme pode-se perceber em:

[...] é um processo tão natural que você acaba nem se ligando de onde veio $o$ insight.

Às vezes tem um job ou uma demanda que pede que você se aprofunde e além das leituras normais você acaba tendo acesso a artigos universitários e outras fontes que te dão munição pro $j o b$, mas às vezes as leituras diárias te ajudam a ter insights.

Quanto ao critério de organização contido no modelo VRIO, percebeu-se nas entrevistas que há uma similaridade na estrutura organizacional nas agências. Isso pode sugerir que, em busca de legitimidade, as empresas tentam se tornar parecidas com o restante do ambiente. Percebeu-se que os recursos informacionais são combinados ao nível da tarefa com conhecimentos técnicos e com recursos humanos para gerar valor aos clientes. Ficou claro também, que o principal limitante da utilização do recurso de informação, dentro da empresa, é a restrição do tempo. Exemplos que reforçam esses argumentos são:

É um processo tão natural que você acaba nem se ligando de onde veio $o$ insight.

[...] tem coisas que eu pego e digo 'vamos testar', entro em contato com o Google, peço betas e vou aplicando.

Não tenho tempo pra cursos, palestras e workshops.

Após essa análise abrangente sobre publicações especializadas buscou-se entender como os executivos avaliam o SoDA e como ele pode conferir vantagem competitiva às agências. Durante as entrevistas, os publicitários afirmaram que o SoDA é relevante para a área. As principais características apontadas foram (1) a questão das tendências de mercado, (2) as opiniões contraditórias expostas e (3) as informações sobre outras agências.

Analisando essas características gerais do SoDA, pode-se concluir que ele é conhecido e lido por trazer, associado ao recurso de informação, a legitimidade perante o mercado (tendências gerais, opiniões de pares, e informações concorrentes). Um excerto que corrobora com essa análise trata de um executivo que lê o SoDA, mesmo entendendo que o mesmo não é relevante para si. Durante as entrevistas, pediu-se uma nota de 1 a 5 para a relevância do SoDA e a resposta foi: 
Eu sou um pouco fora da curva, pois eu leio muita coisa, então para quem não tem essa disponibilidade avalio como um 5, mas para quem acompanha com frequência as notícias ele é mais um instrumento que consolida tudo, seria mais um 3.

Essa frase sugere que, embora esse entrevistado não precise da informação contida no SoDA, ele o lê para se legitimar perante o mercado. Outra inferência, que se faz nesse trecho, é a questão da redução de valor da informação ao decorrer do tempo.

Uma das maiores contribuições que o SoDA traz para seu leitor é a seção sobre as tendências de mercado. No entanto, conforme pode ser visto na Quadro 1, das 22 tendências propostas pela publicação nos últimos 5 anos, 11 foram concretizadas, 8 não ocorreram e em casos 3 ainda não é possível concluir. O fato de apenas metade das tendências terem sido concretizadas reforça o argumento que aponta que os publicitários buscam legitimidade nas publicações especializadas. Essa legitimidade está mais relacionada com o conhecimento das últimas tendências do que com a concretização das mesmas.

Quadro 1. Comparativo das tendências apresentadas pelo SoDA

(continua)

\begin{tabular}{|c|c|c|c|}
\hline Ano & $\begin{array}{c}\text { Tendências } \\
\text { Concretizadas }\end{array}$ & $\begin{array}{l}\text { Tendências } \\
\text { Prescritas }\end{array}$ & $\begin{array}{c}\text { Tendências } \\
\text { Inconclusivas }\end{array}$ \\
\hline \multirow{3}{*}{2011} & $\begin{array}{l}\text { Ano da tecnologia } \\
\text { integrada a } \\
\text { aplicativos com } \\
\text { internet ativada }\end{array}$ & $\begin{array}{l}\text { Compras em grupo } \\
\text { é uma das maiores } \\
\text { tendências em } \\
\text { social shopping }\end{array}$ & \multirow{3}{*}{$\begin{array}{l}\text { Google Instant gerará } \\
\text { mais impressões e cliques } \\
\text { para palavras-chaves dos } \\
\text { resultados preditivos }\end{array}$} \\
\hline & \multirow{2}{*}{$\begin{array}{c}\text { Em } 2012 \text { o } \\
\text { marketing } \\
\text { multitelas se tornará } \\
\text { uma realidade }\end{array}$} & $\begin{array}{c}\text { Twitter e } \\
\text { Foursquare } \\
\text { desaparecerão em } \\
10 \text { anos }\end{array}$ & \\
\hline & & $\begin{array}{l}\text { Redes sociais } \\
\text { baseadas em } \\
\text { localização estão } \\
\text { aqui para ficar e } \\
\text { crescer }\end{array}$ & \\
\hline 2012 - Volume 1 & $\begin{array}{c}\text { Expandir as } \\
\text { animações em Flash } \\
\text { para HTML5 }\end{array}$ & $\begin{array}{c}\text { Em } 2012 \text { se irá além } \\
\text { da análise de sessão } \\
\text { única }\end{array}$ & \\
\hline
\end{tabular}


(conclusão)

\begin{tabular}{|c|c|c|c|}
\hline \multirow[t]{2}{*}{2012 - Volume 2} & $\begin{array}{c}\text { Crescimento } \\
\text { significativo } \\
\text { de usuários de } \\
\text { smartphones nos } \\
\text { próximos } 2 \text { anos }\end{array}$ & \multirow{2}{*}{$\begin{array}{l}\text { Flash é atualmente } \\
\text { a única opção viável } \\
\text { de aceleração por } \\
\text { hardware e internet } \\
\text { explore não pode } \\
\text { ser ignorado em } \\
\text { projetos }\end{array}$} & \\
\hline & $\begin{array}{c}\text { Stage 3D conseguirá } \\
\text { adoção em massa }\end{array}$ & & \\
\hline \multirow[t]{2}{*}{2013 - Volume 1} & $\begin{array}{l}\text { Agências de } \\
\text { publicidade } \\
\text { tentarão gerar } \\
\text { fontes de renda } \\
\text { alternativas } \\
\end{array}$ & \multirow{2}{*}{$\begin{array}{c}2013 \text { será } \\
\text { novamente o ano } \\
\text { do celular }\end{array}$} & \\
\hline & $\begin{array}{c}\text { Um fenômeno } \\
\text { cultural como } \\
\text { Facebook não será } \\
\text { repetido novamente }\end{array}$ & & \\
\hline \multirow{2}{*}{2013 - Volume 2} & \multirow{2}{*}{$\begin{array}{c}\text { Facebook se tornará } \\
\text { mais focado em } \\
\text { interesses no } \\
\text { próximo ano }\end{array}$} & $\begin{array}{c}\text { Google Glass } \\
\text { como exemplo de } \\
\text { dispositivo inovador }\end{array}$ & \\
\hline & & $\begin{array}{c}\text { Até } 2015,75 \% \text { da } \\
\text { população terá } \\
\text { acesso à internet }\end{array}$ & \\
\hline 2014 - Volume 1 & $\begin{array}{l}\text { Quanto menores } \\
\text { os computadores } \\
\text { mais integrados } \\
\text { são às nossas vidas } \\
\text { e quantidades } \\
\text { vastas de dados são } \\
\text { geradas a partir das } \\
\text { nossas ações } \\
\end{array}$ & & \\
\hline 2014 - Volume 2 & & & $\begin{array}{c}\text { Busca por experiências } \\
\text { sensacionais e desconexão } \\
\text { com o mundo físico }\end{array}$ \\
\hline 2015 - Volume 1 & $\begin{array}{l}\text { A educação se } \\
\text { tornará customizada }\end{array}$ & $\begin{array}{c}\text { O número de } \\
\text { wearables se } \\
\text { proliferará como os } \\
\text { tablets no ano de } \\
2012\end{array}$ & \\
\hline 2015 - Volume 2 & $\begin{array}{c}\text { Marcas e empresas } \\
\text { da Fortune } 500 \\
\text { construirão thought } \\
\text { leadership para } \\
\text { gerar visibilidade }\end{array}$ & & \\
\hline
\end{tabular}

Fonte: Elaborado pelos autores, 2016 


\section{CONSIDERAÇÕES FINAIS}

Este trabalho buscou entender como os recursos informacionais, tais como publicações especializadas, são utilizados nas empresas para conferi-las vantagem competitiva. Os resultados foram obtidos por meio de entrevistas com publicitários e também pela análise do conteúdo da publicação internacional SoDA.

A VBR tem como argumento principal que um recurso é considerado estratégico se atender aos critérios do modelo VRIO (valor, raro, inimitável e organização). Segundo as entrevistas realizadas, as publicações atendem a esses critérios à medida que derivem de uma fonte confiável e que sejam relevantes.

As informações são relevantes quando: (1) forem segmentadas, inclusive segmentadas ao nível da tarefa; (2) conferirem legitimidade, tanto dos executivos em relação ao restante da empresa quanto a empresa em relação aos clientes e concorrentes; (3) forem oportunas, a informação deve chegar prontamente aos executivos; (4) quanto mais condensado for o formato de entrega.

Em relação ao critério de raridade, as publicações não podem ser, por definição, raras. No entanto, os executivos buscam esse critério ao acessar informações internacionais. Quanto à inimitabilidade, percebe-se que os recursos informacionais, quando combinados com outros recursos organizacionais, podem auxiliar no mecanismo da ambiguidade causal, gerando resultados difíceis de serem imitados pelos concorrentes e consequentemente, vantagem competitiva em potencial.

Por fim, quanto ao critério de organização contido no modelo VRIO, percebeu-se que o recurso informacional é combinado ao nível da tarefa com os conhecimentos técnicos e com recursos humanos. Pode-se observar, também, que a principal condição de contorno sobre a utilização do recurso de informação nessas empresas é a restrição do tempo.

Essa análise é consoante com a VBR pois reforça seus pilares. Os recursos são heterogêneos entre as organizações e a exploração desses recursos, de forma estratégica, depende de sua combinação com outros recursos e com processos organizacionais.

Especificamente quanto ao SoDA, conclui-se que seu valor está ligado a questão da legitimidade que ele confere às agências que os utilizam. Dessa forma, 
conclui-se que tanto o SoDA e outros recursos informacionais do setor podem ser entendidos como elementos legitimados. Empresas que incluem elementos legitimados em suas estruturas formais aumentam o compromisso dos participantes internos e externos, evitam que suas condutas sejam questionadas, recebem e produzem mais recursos e a incrementar seu potencial de sobrevivência (MEYER; ROWA, 1977). Todas essas consequências favorecem a vantagem competitiva organizacional.

\subsection{IMPLICAÇÕES}

Este estudo colabora com a literatura da VBR à medida que explora como os recursos informacionais podem se tornar recursos estratégicos em empresas com grande turbulência ambiental. Além disso, esse estudo traz a análise do valor do recurso sob a ótica do gestor e não do cliente (SANTOS-VIJANDE; LÓPEZ-SÁNCHEZ; TRESPALACIOS, 2012).

Importante salientar aqui que a generalização, para qualquer ambiente turbulento, não deve ser automática e que a contribuição desse estudo é no sentido de identificar como o recurso informacional se torna um recurso estratégico para a empresa.

Outra implicação para os gestores é direcionada aos editores de periódicos científicos. Artigos científicos dificilmente serão considerados recursos importantes pelos publicitários. A razão para isso é que eles são muito mais extensos do que os publicitários se comprometem em ler, e em geral não respeitam a questão da oportunidade. Ou seja, artigos científicos demoram demais para chegar às mãos dos publicitários e quando chegam são longos demais para serem lidos.

Se os periódicos científicos quiserem se tornar mais relevantes para os profissionais de publicidade, eles precisarão ter versões extremamente reduzidas e o tempo entre pesquisas e publicação deve ser reduzido.

\subsection{LIMITAÇÕES E PESQUISAS FUTURAS}

Esse trabalho não foi concluído sem limitações. Em primeiro lugar foram realizadas entrevistas estruturadas. Esse método de entrevistas, embora auxilie a 
comparação dos dados entre respondentes, acaba por reduzir a profundidade das respostas. Adicionalmente, trata-se de estudo qualitativo e, portanto, qualquer generalização para outros ambientes deve ser realizada com cautela. Defende-se, no entanto, que as categorias encontradas aqui possam ser um guia importante para análises em outros estudos.

Dada esta limitação, estudos futuros podem analisar como os recursos informacionais são valorizados em outros ambientes, ou mesmo, utilizar-se de outros métodos de pesquisa para reforçar os achados aqui expostos. Outro caminho para pesquisas é aprofundar o estudo da interação dos recursos informacionais com outros recursos ou capacidades organizacionais. Pode-se demonstrar os mecanismos organizacionais que combinam esses recursos com outros, afim de gerar vantagem competitiva.

\section{REFERÊNCIAS}

ABELA, J. A. Las Técnicas de Análisis de Contenido: una revisión actualizada. 2002.

BARNEY, J. Firm Resources and Sustained Competitive Advantage. Journal of Management, v. 17, n. 1, p. S. 99-120, 1991.

BARNEY, J.; HESTERLY, W. S. Strategic Management and Competitive Advantage. 4. ed. [s.l: s.n.].

BOCCONCELLI, Roberta et al. SMEs and Marketing: A Systematic Literature Review. International Journal of Management Reviews, v. 0, p. 1-28, 2016.

CÁCERES, P. Análisis Cualitativo de Contenido: Una alternativa metodológica alcanzable. Psicoperspectivas. Indivíduo y Sociedad, v. 2, n. 1, p. 53-82, 2008.

CRUBELLATE, J. M; PASCUCCI, L; GRAVE, P. S. Contribuições para uma visão baseada em recursos legítimos. RAE-Revista de Administração de Empresas, v. 48, n. 4, 2008. 
DAY, G. S. The Capabilities of Market-Drive Organizations. Journal of Marketing, v. 58, n. 4, p. 37-52, 1994.

DAY, G. S. Closing the Marketing Capabilities Gap. Journal of Marketing, v. 75, n. 4, p. 183-195, 2011.

DEEPHOUSE, D. L.; SUCHMAN, M. Legitimacy in Organizational Institutionalism. The Sage handbook of Organizational Institutionalism, v. 49, p. 77, 2008.

DIMAGGIO, P. J.; POWELL, W. W. The iron cage revisited: Institutional isomorphism and collective rationality in organizational fields. American Sociological Review, v. 48, n. 2, p. 147-160, 1983.

FRISKE, W. From Strategy to Performance: An Investigation of the Factors Affecting Marketing Plan Implementation. 2015. 74p.

GRANT, R. M. The Resource-based theory of Competitive Advantage: implications for strategy formulation. California Management Review, v. 33, n. 3, p. 114-135, 1991.

HAMBRICK, D. C.; MASON, P. A. Upper echelons: The organization as a reflection of its top managers. Academy of management review, v. 9, n. 2, p. 193-206, 1984.

KOHLI, A. K.; JAWORSKI, B. J. Market Orientation: The Journal of Marketing, v. 54, n. 2, p. 1-18, 1990

KOZLENKOVA, I. V.; SAMAHA, S. A.; PALMATIER, R. W. Resource-based theory in marketing. Journal of the Academy of Marketing Science, v. 42, n. 1, p. 1-21, 2013.

KRUSH, M.; AGNIHOTRI, R.; TRAINOR, K. A Contingency model of Marketing Dashboards and their influence on Marketing Strategy Implementation speed and market information Management Capability. European Journal of Marketing, v. 50, n. 12, p. 2069, 2016. 
LEEFLANG, P. S.H.; VERHOEF, P. C.; DAHLSTRÖM, P.; FREUNDT, T. Challenges and solutions for marketing in a digital era. European Management Journal, v. 32, n. 1, p. 1-12, 2014.

MARCONI, M.; LAKATOS, E. M. Técnicas de Pesquisa. São Paulo: Atlas, v. 6, 2007.

McALISTER, L. Rigor versus method imperialism. Journal of the Academy of Marketing Science, v. 44, n. 5, p. 565-567, 2016.

MEYER, J. W.; ROWAN, B. Institutionalized Organizations: Formal structure as myth and ceremony. American Journal of Sociology, p. 340-363, 1977.

MITHAS, S.; RAMASUBBU, N.; SAMBAMURTHY, V. How information management capability influences firm performance. MIS Quarterly: Management Information Systems, v. 35, p. 237-256, 2011.

MORGAN, N. Marketing and business performance. Journal of the Academy of Marketing Science, v. 40, n. 1, p. 102-119, 2012.

NARVER, J. C.; SLATER, S. F. The Effect of a Market Orientation on Business Profitability. The Journal of Marketing, v. 54, n. 4, p. 20-35, 1990.

PFEFFER, J.; SALANCIK, G. The External Control of Organizations: a resource dependence perspective. New York: Harper \& Row, 1978.

PRIEM, R. L.; BUTLER, J. E. Is the Resource-Based "View" a Useful Perspective for Strategic Management Research? Academy of Management Journal, v. 26, n. 1, p. 22-40, 2001.

RODRÍGUEZ, J. Métodos de Investigación Cualitativa. Revista de Investigación Silogismo, v. 1, n. 8, 2011. 
ROSSONI, L. O que é Legitimidade Organizacional? Organizações \& Sociedade, v. 23, n. 76, 2016.

SANTOS-VIJANDE, M. L.; LÓPEZ-SÁNCHEZ, J. Á.; TRESPALACIOS, J. A. How Organizational Learning affects a firm's flexibility, competitive strategy, and performance. Journal of Business Research, v. 65, n. 8, p. 1079-1089, 2012.

SCOTT, W. R. Institutions and Organizations. 2. ed. London: SAGe, 2001.

SCOTT, W. R. Approaching adulthood: the maturing of institutional theory. Theory and society, v. 37, n. 5, p. 427-442, 2008.

SUCHMAN, M. C. Managing legitimacy: Strategic and Institutional Approaches. Academy of Management Review, v. 20, n. 3, p. 571-610, 1995.

UBAVIĆ, P. Informational Resources Management. Ekohomnka, v. 61, n. 1, p. 161$171,2015$.

VEIGA, L.; GONDIM, S. M. A Utilização de métodos qualitativos na Ciência política e no Marketing político. Opinião Pública, v. 7, n. 1, p. 1-15, 2001.

WANG, R.; GUPTA, A.; GREWAL, R. Mobility of Top Marketing and Sales Executives in Business- to-Business Markets : A Social Network Perspective. Journal of Marketing Research, n. 4, p. 65-670, 2017.

ZUCKER, G. Institutional Theories of Organization. Annual Review of Sociology, v. 13, n. 1, p. $443-464,1987$.

Recebido em: 14 de dezembro de 2016 Aceito em: 06 de novembro de 2017 